\title{
Blended Learning
}

\section{Parthsarthi Pandey}

Principal, Gandhi Vocational College, (An Autonomous College), Guna, (M.P.) India

Corresponding author: parthsarthi1974@gmail.com

Received: 10 Oct., 2020

Revised: 25 Nov., 2020

Accepted: 12 Dec., 2020

\begin{abstract}
A critical component of blended learning is that technology is combined with face-toface instruction to enhance learning for students. Without this essential component, blended learning would be no different than when a teacher projects online curriculum to the entire class on a whiteboard. A blended learning methodology enables students to utilize technology to learn in a way that best meets their needs while in an environment that encourages creativity, critical thinking, and problem solving. The focus on how technology is used in a blended learning approach is critical for separating it from being a technology-rich classroom. Blended learning is an instructional approach that enables teachers to have more time to personalize learning for their students. Learning is personalized so that students in a blended learning environment have some control over the pace of their learning.
\end{abstract}

Keywords: Blended learning, Technology-enabled learning, blended learning models

Balancing traditional instructional strategies with technology can engage students in authentic learning experiences focused on exploration, creativity, critical thinking, communication, and collaboration. The expansion of information and communication technologies is central to social, cultural, and technological changes that are impacting teaching and learning. Blended learning has rapidly emerged in schools as a popular methodology for personalizing instruction to improve student learning. Teachers are blending best practices in a brickandmortar environment along with meaningful online experiences to provide student-centered learning opportunities for all students. Technology is a tool that can be used by teachers to

How to cite this article: Pandey, P. (2020). Blended Learning. TechnoLearn: An International Journal of Educational Technology, 10(1\&2): 41-46. 
p

Pandey

accommodate the learning needs of more students by adapting how content and instruction are delivered. Personalizing learning through a blended approach is more attainable for an individual classroom teacher, who is responsible for supporting a variety of students across different academic levels. Teachers can adapt face-to-face and online instruction to meet the diverse needs of all students within the classroom or be as uniform as a traditional educational environment based on the academic needs of students. Teachers can address the achievement gap between groups of students by adapting instruction to the specific needs of individual students while increasing student agency. "A great teacher adjusts to the learner, not the other way around".

\section{Significance of Blended Learning}

It is important to examine the experiences of teachers as they are the most important component of any effective instructional approach. Building capacity in implementing innovative strategies to support 21st century learners is crucial for teachers. It is imperative for educational leaders to provide professional development focused on utilizing these strategies to address student variance. Students in blended learning environments are experiencing improved learning outcomes, because teachers are focusing on how students learn best, rather than on the technology itself. Providing a student-centered learning environment to address the diverse needs of all learners while facilitating the development of $21^{\text {st }}$ century skills is dependent upon the knowledge, ability and beliefs of teachers.

Technology-enabled learning experiences have been successfully utilized in blended learning environments to personalize learning, increase student agency, and narrow the digital use divide. These learning experiences are designed to incorporate technology so that educators can "expand growth possibilities for all students while affording historically disadvantaged students greater equity of access to high-quality learning materials, expertise, personalized learning, and tools for planning for future education". Emerging technologies provide educators with opportunities to enhance learning in ways that never existed.

\section{Blended Learning Pedagogy}

New forms of learning utilizing technology to improve engagement are aligned with the development of 21st century skills and competencies. Blended learning is an instructional methodology that has emerged as a way to provide meaningful learning experiences for all students. This methodology is growing as a student centered, innovative delivery approach that enhances student learning outcomes through student engagement. Effectively integrating technology into instructional practices can be a challenge for teachers to manage without understanding the role it should play in instruction. The use of technology, in a blended learning environment, impacts student learning outcomes by elevating instructional strategies 
that work, not by diminishing or replacing them with. Blended learning goes beyond putting devices technology. It is based on teachers who incorporate online and face-to-face instruction to ensure academic growth for all students through personalized learning. Blended learning represents a paradigm shift from the traditional factory-model to a student-centered instructional model. Teachers are utilizing blended learning to create innovative opportunities to maximize student learning outcomes. A blended learning instructional model benefits all students through face-to-face interaction with a teacher, along with meaningful online learning experiences. The flexibility for teachers to adapt a blended learning approach that best fits the needs of their students is crucial to a successful implementation. Students in a blended learning environment have access to an extensive amount of online resources and are guided by teachers who provide quality learning experiences that extend beyond the classroom.

\section{Models Of Blended Learning}

Extreme models of blended learning are designed so that students choose their own learning path based on their interests and needs. Some blended learning models are organized so that students can choose where they want to work on their online assignments. The place in a blended learning environment refers to a learning environment where students are not restricted to learning within the four walls for the classroom. A blended learning approach involves students participating in face-to-face learning experiences in a supervised classroom. Students attend classes in a physical building and meet face-to-face with a teacher while using technology to enhance learning. Blended learning is an effective pedagogical approach for enabling students to experience the essential socialization and academic support of being in a brick-and-mortar facility combined with technology-enabled learning experiences. The belief that school should be more than a virtual learning environment is a shared concern of many parents and teachers. Teachers report that providing guided instruction is difficult in a virtual environment where there is no face-to-face interaction. Teachers in a blended learning environment manage and provide guidance to students while supporting the development of digital citizenship and online safety skills. Students learn in a safe physical environment while building meaningful relationships with peers and teachers.

Educators must consider the devices and infrastructure available to schools prior to implementing a blended learning instructional model. They must also use their professional knowledge and resources to select the appropriate blended learning model that best meets the needs of their students. However, most blended learning models are classified as one of the four main instructional models: Rotation, Flex, A La Carte, and Enriched Virtual (Horn \& Staker, 2015; Powell et al. 2015; Staker \& Horn, 2012). The Station Rotation, Lab Rotation, and Flipped Classroom models of blended learning are examples of sustaining hybrid innovations, because they incorporate traditional face-to-face and online learning. The Individual Rotation, Flex, A La Carte, and Enriched Virtual models are examples of disruptive models of blended 
p

learning. Disruptive models of blended learning utilize traditional classroom experiences in new and different ways.

The Rotation Model is designed for students to rotate through face-to-face and online learning experience at the discretion of the teacher. These experiences could include whole-group instruction, small-group instruction, one-on-one tutoring, peer groups, project-based learning, and paper-pencil activities in addition to the online component. The teacher controls the amount of time students spend at each modality and signals when it is time for students to move on to the next activity. This model is structured so that teachers have the opportunity to provide targeted instruction while keeping all students actively engaged in the learning process. Teachers use online activities during the rotation for collecting data to drive instruction to address the individual learning needs of students in the classroom. Teachers utilize technology enabled adaptive learning experiences to provide individual students with the content they need at the time they need it. Some different types of Rotation Models that are popular in schools:

* Station Rotation,

* Lab Rotation,

* Flipped Classroom, and

Individual Rotation Model of blended learning.

1. The Station Rotation Model is the most common blended learning model in schools and is similar to how teachers, especially those in primary grades, have structured learning centers for decades. Students rotate through planned learning experiences within a single or multiple classroom focused on a specific content area. Students rotate through the assigned activities when the teacher announces or signals that it is time to move on to the next activity.

2. A Lab Rotation Model of blended learning involves students rotating from the classroom to a computer lab for online learning experiences. This model is structured basically the same as the Station Rotation Model except students leave the physical space of the classrooms for the online portion. The implementation of this model requires an additional staff position to supervise students in the computer lab but decreases the number of students in the classroom who are working through other rotations with the teacher, individually or in groups. Although students are being supervised by another staff member in the lab, classroom teachers still use data from the online portion to drive instruction across modalities.

3. The Flipped Classroom Model is designed for students to get more of the direct instruction content outside of the school day while using class time to focus on guided practice or projects facilitated by the teacher. Teachers using this model flip the assignments so that content delivery occurs outside of the classroom while using valuable class time to engage students in authentic learning activities. Students in a flipped classroom environment participate in 
online learning or lectures independently and use the time in the classroom for face-to-face instruction and support. Students have access to the specific digital content necessary to address their individual learning needs as they work at their own pace to achieve mastery. The teacher takes on a coaching or facilitating role during class time.

4. The Individual Rotation Model is more personalized for students because they do not rotate through the same learning experiences through the school day. Student learning experiences are specifically geared toward their individual needs, so they have a specific playlist of activities designed for them. Teachers or adaptive software create personalized playlists for students to rotate through during the school day. Each student has their own unique schedule each day based on their immediate learning needs. Students are expected to complete customized assignments within the rotation.

5. The Flex Model centers around online learning with some face-to-face activities. Credit recovery courses and advanced placement classes are examples of programs using this model to support students who need access to specific content. Teachers using this model use online learning as the main method of instruction to address specific learning needs and face-to-face support is utilized as needed. Students follow customized, fluid schedules where they are involved with active-learning opportunities personalized to address their individual needs. The Flex Model is more personalized than the Individual Rotation Model because all students are working on individualized course curriculum while the focus is more on technology-enabled learning experiences with the teachers there to provide support on an as-needed basis.

6. The A La Carte Model is a course that is taken online to accompany other face-to-face learning experiences. The teacher is normally an online instructor who is not necessarily located at the student's physical school. This model is more common in secondary schools. This model is for students who attend traditional classes in addition to virtual classes with an online teacher which is useful in situations where courses might not be available at certain schools.

7. The Enriched Virtual Model refers to students who have some face-to-face learning experiences with a teacher, but complete the remaining coursework remotely. Many of these models started specifically as an online school and then educators incorporated brick-andmortar activities to provide a blended experience for students. Generally, the students have the same teacher for the online and face-to-face portions of the course. Although some formal face-to-face learning time with their teacher is required on a regularly scheduled basis, most of their learning activities are completed online, outside the physical building.

\section{REFERENCES}

Bloom, B.S. 1984. The 2 sigma problem: The search for methods of group instruction as effective as one-to-one tutoring. Educational Researcher, 13(6): 4-16. 
P Pandey

Christensen Institute. (n.d.). Blended learning models. Blended Learning Universe. https://www.blendedlearning. org/models/

Frey, N., Fisher, D. and Pumpian, I. 2013. Quality in a blended learning classroom. Principal Leadership, 14(2): 60-63.

Suprabha, K. and Subramonian, G. 2015. Blended learning approach for enhancing students' learning experiences in a knowledge society. Journal of Educational Technology, 11(4): 1-7. 